\title{
Hanno collaborato a questo numero
}

\section{Daniele Benzi}

Tras una estancia de investigación en Cuba, Venezuela y Bolivia, actualmente se está especializando en estudios latinoamericanos en la Unam (Universidad nacional autónoma de México). Acaba de presentar su tesis doctoral sobre Cooperación y desarrollo al atardecer del neoliberalismo: una aproximación al Alba en el Departamento de sociología y ciencia política de la Universidad de Calabria. Colabora con la revista mexicana «Revuelta», el proyecto «Agorá» de Flacso-Ecuador y con la revista on-line de la Asociación cultural Punto Rosso.

\section{Luca Bianchi}

Dottorando in Scienze integrate per la sostenibilità territoriale dell’Università degli studi di Trieste.

\section{Antonio Casamento}

Lettore vacataire, Université Stendhal Grenoble 3, Francia.

\section{Luiz Antônio Cunha}

Professor titular de Sociologia da educação na Universidade Federal do Rio de Janeiro onde coordena o Observatório da laicidade do Estado. É membro do Conselho nacional de educação em Brasília.

\section{Barbara D'Introno}

Psicologa, è impegnata nel Progetto Stella Polare dove si occupa di immigrazione femminile.

\section{Caterina Dolcher}

Avvocato è stata, dal 2003 al 2008, difensore civico della Regione Friuli Venezia Giulia e, per alcuni anni, professore a contratto di Diritto di famiglia presso l'Università degli studi di Trieste. Si è occupata di rapporti fra il cittadino e la Pubblica amministrazione pubblicando alcuni saggi in materia.

\section{João Marcelo Martins Calaça}

Especialista em Direito do trabalho e processo do trabalho, exerce a função de analista judiciário no Tribunal regional do trabalho do Rio de Janeiro. É pós-graduado em Finanças internacionais e política macroeconômica, Fundação Getúlio Vargas (Brasil), e em Relações econômicas internacionais, Universidade politécnica de Madrid. Esta cursando o mestrado em Integração economica internacional e União Européia, Universidad politecnica de Madrid. 


\section{Ana Maruchniak}

Nacida a Ried en Austria, nacionalizada Argentina, trabajador social en Buenos Aires, con alta experiencia laboral en varias instituciones y universidades, como docente y coordinador en el área social.

\section{Ana Cecilia Prenz Kopušar}

Ricercatrice di Letteratura spagnola presso la Facoltà di lettere e filosofia dell’Università di Trieste.

\section{Graciela Racedo}

Profesora universitaria de Historia en la Usal-Universidad del Salvador, Buenos Aires.

Por su ensayo, El gaucho. Formación, significancia y vigencia de un mito, obtuvo en el 2005 el Premio Eduardo Mallea del Gobierno de la Ciudad de Buenos Aires.

\section{Emir Sader}

Professor de Política na Universidade de Campinas (Unicamp) e coordenador do Curso de especialização em Políticas sociais na Universidade do Estado do Rio de Janeiro (Uerj). Atualmente dirige o Laboratório de políticas públicas na Uerj, onde é professor de sociologia.

\section{Margherita Villa}

Architetto bioclimatico. Ha svolto attività professionali in alcuni Paesi africani. Attualmente collabora con due Ong per progetti nel settore energetico. 